\title{
Tracking excess weight and obesity from childhood to young adulthood: a 12-year prospective cohort study in Slovenia
}

\author{
Gregor Starc* and Janko Strel \\ Faculty of Sport, University of Ljubliana, Gortanova 22, SI-1000 Ljubljana, Slovenia
}

Submitted 20 April 2009: Accepted 28 February 2010: First published online 15 April 2010

\begin{abstract}
Objective: The objective was to examine the tracking of obesity from childhood to young adulthood in Slovenia.

Subjects: A subsample included 4833 children from the Slovenian national sample ( $n$ 21 777) who were included in the SLOFIT monitoring system from 1997 to 2008, with complete data at 7 years and 18 years.

Design: A 12-year prospective cohort study. Height, weight and triceps skinfold thickness (TSF) were measured at 7, 11, 14 and 18 years. The BMI cut-off points of the International Obesity Taskforce were used to identify excess weight and obesity. Setting: The survey was conducted in Slovenian primary and secondary schools from 1988 to 2008 but only the data from the measurements in 1997, 2001, 2004 and 2008 are presented.

Results: Height, weight and BMI at 18 years were well predicted from childhood and became more predictable with age, while TSF was not. Obese and overweight children had the greatest risk of becoming obese or overweight young adults. The history of their weight shows that $40.0 \%$ of males and $48 \cdot 6 \%$ of females who were obese at 18 years had already been obese at 7 years.

Conclusions: Overweight or obese Slovenian children are more likely to become overweight or obese adolescents and young adults than reported in other similar European and American studies, which indicates the need for early prevention and treatment of excess weight and obesity.
\end{abstract}

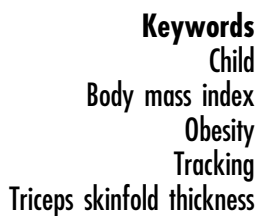

In recent decades, excess weight and obesity have been acknowledged as some of the fastest growing non-transmissible health problems worldwide ${ }^{(1)}$. An increase in the prevalence of excess weight and obesity is a particular concern because it has proven to be an important factor for numerous chronic diseases and other health disorders among adults $^{(2-8)}$ as well as among children ${ }^{(9-14)}$. Consequently, obesity not only worsens the quality of life of affected individuals but also increases public and personal health expenditures ${ }^{(15-19)}$. Obesity is a burdening factor in all respects; it should become a public health priority in developed and developing countries, and it is from this perspective of prevention that the relationship between childhood obesity and young adult obesity has been investigated. Several studies have shown a tendency of those who are overweight or obese as children to remain overweight or obese as adolescents and adults ${ }^{(20-28)}$. However, much of the research has been conducted in high-income and predominantly Western countries, while only limited data are available for middle- or low-income countries and post-socialist countries (like Slovenia), which quickly and abruptly adopted capitalist economies and consumerist lifestyles, including eating habits and physical activity patterns. Longitudinal research on these topics from rapidly changing societies might provide new insights, as well as enable comparison and consequent prediction of obesity trends among children and adults in these societies.

The present study focused on the tracking of obesity and excess weight by measuring triceps skinfold thickness (TSF) and BMI from childhood to young adulthood among Slovenian schoolchildren who entered primary school in the school years 1996-1997 and turned 18 years of age in the school years 2007-2008. Numerous studies have identified two critical periods in childhood for the development of obesity ${ }^{(27,29-34)}$ : the period of adiposity rebound between 5 years and 7 years and adolescence. According to these findings, the analysis includes the measurements at 7,11 and 14 years to establish the excess weight and obesity outcome at 18 years. We used longitudinal data to investigate the relationship between height, weight, BMI and TSF to assess: (i) associations between the height of children and young adults; (ii) the extent to which obese or overweight children become obese or overweight young adults; and (iii) whether obese or overweight young adults were obese or overweight children. 


\section{Methods}

\section{Subjects}

The 1988-1990 Slovenian cohort included 21777 children (94.2\% of the children who started primary school in September 1996) who enrolled in the SLOFIT system ${ }^{(35)}$ by the written consent of their parents, who were born between January 1988 and November 1990. Information on weight and height in the last year of secondary school at an average age of 18.7 (SD 0.3) years was obtained in April 2008 for 4833 children. This analysed subsample included children whose information on body weight and body height was obtained both in the first grade of primary school and the last year of 4-year secondary school. Children with incomplete information in the 1997 ( $n$ 1624) or 2008 measurements ( $n$ 17 438) were excluded. The subsample did not include pupils who were enrolled in the 3-year vocational schools and therefore finished their schooling in 2007 or who were older than 19 years in April 2008 ( $n$ 2715). A considerable reduction of the sample in 2008 occurred because many pupils either refused to participate in the measurements after they turned 18 and no longer needed the written consent of their parents, because they could not attend the measurements due to health problems, because they refused to be weighed, or because they did not continue their schooling after primary school.

The present study presents the data from the 1997 SLOFIT measurement and the 2001, 2004 and 2008 follow-ups. The age of the participating children was calculated to the closest month on the day of the measurements every year; the average age at the 1997 measurement was $7 \cdot 7 \pm 0 \cdot 3$ years $(92.8$ (SD 3.7) months for males and 92.7 (SD 3.9) months for females). Mean values and standard deviations of the population sample and the subsample were very similar, with differences in mean height below $5 \mathrm{~mm}$, differences in mean weight below $0.6 \mathrm{~kg}$ (except in 11-yearold females in whom the average weight of the subsample was $1 \cdot 1 \mathrm{~kg}$ smaller), differences in mean TSF below $0.4 \mathrm{~mm}$, and differences in mean BMI below $0 \cdot 4 \mathrm{~kg} / \mathrm{m}^{2}$ at all ages.

\section{Measurements}

Height, weight and TSF were measured by trained physical education teachers who had completed a 30-h course in anthropometric measurement during their studies.
Subjects were measured each April at ages 7, 11, 14 and 18 years \pm 1 year. Measurements were organised in school gyms between 08.00 and 14.00 hours. Subjects were weighed barefoot in their shorts and T-shirts to the nearest $0.5 \mathrm{~kg}$ with portable scales of various brands; height was measured with stadiometers of various brands to the nearest $0.5 \mathrm{~cm}$; triceps skinfold was measured with Holtain-Tanner callipers to the nearest $\mathrm{mm}$. All instruments were calibrated once at the beginning of measurements. Data were checked to detect coding errors. BMI was calculated at each age. The cut-off points of the International Obesity Taskforce (IOTF) ${ }^{(36)}$ for each 0.5 year were used to define overweight and obese children. These criteria identify BMI values for each age associated with a predicted BMI of $30 \mathrm{~kg} / \mathrm{m}^{2}$ at 18 years. Age-specific BMI (weight in $\mathrm{kg}$ divided by height in $\mathrm{m}^{2}$ ) was calculated for each individual using the nearest tabulated age method. Age-specific values are given in Table 1 .

\section{Statistics}

Partial correlation coefficients, adjusted for dates of measurement, were calculated between height, weight, TSF and BMI at ages 7,11, 14 and 18 years. To reduce skewness of the weight, TSF and BMI distributions, correlations were also performed by using Lg (weight), Lg (TSF), Lg (BMI) and Sqrt for all three variables. Differences between correlations using transformed and untransformed variables proved to be trivial $(-0.26$ to $0 \cdot 24)$; therefore, only correlations of untransformed variables are presented. BMI categories at 7, 11, 14 and 18 years were cross-classified. Percentages are shown primarily to show outcomes for the obese children and to show the BMI distribution at 7 years for the different BMI groups at 18 years. All analyses were performed using SPSS $15 \cdot 0$ for Windows (SPSS Inc., Chicago, IL, USA).

\section{Results}

Mean (SD) height, weight, TSF and BMI for subjects 7-18 years for males and females are shown in Table 2.

\section{Height, weight, BMI and TSF}

Correlations between height at 7 and 18 years in Table 3 tended to be strong for males $(r=0.69, P<0.001)$ and

Table 1 Percentage of normal, overweight and obese children at 7, 11, 14 and 18 years

\begin{tabular}{|c|c|c|c|c|c|c|c|c|c|c|c|c|}
\hline \multirow[b]{3}{*}{ Age } & \multicolumn{6}{|c|}{ Males } & \multicolumn{6}{|c|}{ Females } \\
\hline & \multicolumn{2}{|c|}{ Normal } & \multicolumn{2}{|c|}{ Overweight } & \multicolumn{2}{|c|}{ Obese } & \multicolumn{2}{|c|}{ Normal } & \multicolumn{2}{|c|}{ Overweight } & \multicolumn{2}{|c|}{ Obese } \\
\hline & $\%$ & $n$ & $\%$ & $n$ & $\%$ & $n$ & $\%$ & $n$ & $\%$ & $n$ & $\%$ & $n$ \\
\hline 7 years & $81 \cdot 1$ & 1712 & $13 \cdot 2$ & 279 & $5 \cdot 7$ & 121 & $82 \cdot 5$ & 1871 & $13 \cdot 1$ & 296 & $4 \cdot 4$ & 100 \\
\hline 11 years & $76 \cdot 8$ & 1471 & $18 \cdot 7$ & 358 & $4 \cdot 5$ & 87 & $81 \cdot 8$ & 1686 & $15 \cdot 9$ & 327 & $2 \cdot 4$ & 49 \\
\hline 14 years & $78 \cdot 7$ & 1663 & $17 \cdot 6$ & 372 & $3 \cdot 6$ & 77 & $87 \cdot 2$ & 1977 & $11 \cdot 2$ & 255 & $1 \cdot 5$ & 35 \\
\hline 18 years & 74.5 & 1573 & $22 \cdot 7$ & 479 & $2 \cdot 8$ & 60 & $87 \cdot 4$ & 1982 & $11 \cdot 0$ & 250 & $1 \cdot 5$ & 35 \\
\hline
\end{tabular}


Table 2 Mean height, weight, TSF and BMI at 7-18 years

\begin{tabular}{|c|c|c|c|c|c|c|c|c|}
\hline & \multicolumn{2}{|c|}{ Height (m) } & \multicolumn{2}{|c|}{ Weight (kg) } & \multicolumn{2}{|c|}{ TSF (mm) } & \multicolumn{2}{|c|}{ BMI $\left(k g / m^{2}\right)$} \\
\hline & Mean & SD & Mean & SD & Mean & SD & Mean & SD \\
\hline \multicolumn{9}{|l|}{ Males } \\
\hline 7 years $(n 2112)$ & $1 \cdot 29$ & 0.05 & $28 \cdot 01$ & $5 \cdot 30$ & $9 \cdot 76$ & $4 \cdot 22$ & $16 \cdot 62$ & $2 \cdot 35$ \\
\hline 11 years $(n 1917)$ & $1 \cdot 51$ & 0.07 & $43 \cdot 54$ & $9 \cdot 77$ & $12 \cdot 63$ & $6 \cdot 10$ & $18 \cdot 93$ & $3 \cdot 30$ \\
\hline 14 years $(n 2112)$ & $1 \cdot 72$ & 0.08 & $62 \cdot 04$ & $11 \cdot 70$ & $10 \cdot 88$ & $5 \cdot 84$ & $20 \cdot 86$ & $3 \cdot 18$ \\
\hline 18 years $(n 2112)$ & $1 \cdot 80$ & 0.06 & $75 \cdot 64$ & $11 \cdot 13$ & $10 \cdot 74$ & $5 \cdot 49$ & $23 \cdot 27$ & 3.06 \\
\hline \multicolumn{9}{|l|}{ Females } \\
\hline 7 years $(n 2267)$ & $1 \cdot 28$ & 0.06 & $27 \cdot 04$ & $5 \cdot 03$ & $10 \cdot 98$ & $4 \cdot 15$ & $16 \cdot 34$ & $2 \cdot 27$ \\
\hline 11 years $(n 2065)$ & $1 \cdot 52$ & 0.07 & $43 \cdot 33$ & $9 \cdot 57$ & $12 \cdot 85$ & $5 \cdot 61$ & $18 \cdot 63$ & $3 \cdot 18$ \\
\hline 14 years $(n 2267)$ & $1 \cdot 65$ & 0.06 & $55 \cdot 72$ & $8 \cdot 66$ & $14 \cdot 17$ & $5 \cdot 25$ & $20 \cdot 56$ & $2 \cdot 81$ \\
\hline 18 years $(n 2267)$ & $1 \cdot 67$ & 0.06 & $60 \cdot 59$ & $9 \cdot 08$ & $15 \cdot 54$ & $5 \cdot 33$ & $21 \cdot 81$ & $2 \cdot 89$ \\
\hline
\end{tabular}

TSF, triceps skinfold thickness.

Table 3 Partial correlation matrix of height, weight, TSF and BMI at 7-18 years

\begin{tabular}{|c|c|c|c|c|c|c|c|c|c|c|c|c|c|c|c|c|}
\hline & \multicolumn{8}{|c|}{ Males } & \multicolumn{8}{|c|}{ Females } \\
\hline & \multicolumn{2}{|c|}{7 years } & \multicolumn{2}{|c|}{11 years } & \multicolumn{2}{|c|}{14 years } & \multicolumn{2}{|c|}{18 years } & \multicolumn{2}{|c|}{7 years } & \multicolumn{2}{|c|}{11 years } & \multicolumn{2}{|c|}{14 years } & \multicolumn{2}{|c|}{18 years } \\
\hline & $r$ & $n$ & $r$ & $n$ & $r$ & $n$ & $r$ & $n$ & $r$ & $n$ & $r$ & $n$ & $r$ & $n$ & $r$ & $n$ \\
\hline \multicolumn{17}{|l|}{ Height } \\
\hline 7 years & 1.00 & 2112 & 0.87 & 1917 & 0.78 & 2112 & 0.69 & 2112 & $1 \cdot 00$ & 2267 & 0.84 & 2065 & $0 \cdot 74$ & 2267 & 0.65 & 2267 \\
\hline 11 years & & & $1 \cdot 00$ & 1917 & 0.86 & 1917 & $0 \cdot 70$ & 1917 & & & $1 \cdot 00$ & 2065 & $0 \cdot 74$ & 2065 & 0.60 & 2065 \\
\hline 14 years & & & & & 1.00 & 2112 & 0.72 & 2112 & & & & & 1.00 & 2267 & 0.91 & 2267 \\
\hline 18 years & & & & & & & 1.00 & 2112 & & & & & & & 1.00 & 2267 \\
\hline \multicolumn{17}{|l|}{ Weight } \\
\hline 7 years & 1.00 & 2112 & 0.86 & 1917 & 0.78 & 2112 & 0.64 & 2112 & 1.00 & 2267 & 0.85 & 2065 & 0.73 & 2267 & 0.64 & 2267 \\
\hline 11 years & & & 1.00 & 1917 & 0.87 & 1917 & 0.72 & 1917 & & & 1.00 & 2065 & 0.83 & 2065 & 0.68 & 2065 \\
\hline 14 years & & & & & 1.00 & 2112 & 0.78 & 2112 & & & & & 1.00 & 2267 & 0.82 & 2267 \\
\hline 18 years & & & & & & & 1.00 & 2112 & & & & & & & 1.00 & 2267 \\
\hline \multicolumn{17}{|l|}{ TSF } \\
\hline 7 years & 1.00 & 2071 & 0.66 & 1882 & 0.52 & 2071 & 0.39 & 2071 & 1.00 & 2222 & 0.62 & 2029 & 0.49 & 2222 & 0.35 & 2219 \\
\hline 11 years & & & 1.00 & 1917 & 0.70 & 1917 & 0.49 & 1917 & & & 1.00 & 2065 & 0.62 & 2065 & 0.45 & 2064 \\
\hline 14 years & & & & & 1.00 & 2112 & 0.50 & 2112 & & & & & 1.00 & 2267 & 0.49 & 2264 \\
\hline \multirow{2}{*}{\multicolumn{17}{|c|}{ BMI }} \\
\hline & & & & & & & & & & & & & & & & \\
\hline 7 years & 1.00 & 2112 & 0.80 & 1917 & 0.71 & 2112 & 0.58 & 2112 & 1.00 & 2267 & 0.78 & 2065 & 0.66 & 2267 & 0.59 & 2267 \\
\hline 11 years & & & 1.00 & 1917 & 0.84 & 1917 & 0.70 & 1917 & & & 1.00 & 2065 & 0.82 & 2065 & 0.70 & 2065 \\
\hline 14 years & & & & & 1.00 & 2112 & 0.78 & 2112 & & & & & 1.00 & 2267 & 0.79 & 2267 \\
\hline 18 years & & & & & & & $1 \cdot 00$ & 2112 & & & & & & & $1 \cdot 00$ & 2267 \\
\hline
\end{tabular}

TSF, triceps skinfold thickness.

females $(r=0 \cdot 65, P<0 \cdot 001)$. As expected, correlations were greater over shorter intervals. Males had higher correlations than females at 7 and 11 years, but lower correlations at 14 years. These sex differences reflect the differences in the pubertal growth spurt, which occurs later for males ${ }^{(37)}$. At 14 years, the growth period of females is nearing the end and the difference between the average height of females at ages 14 and 18 years, shown in Table 2, was only $2 \mathrm{~cm}$, while the difference between the average height of males in the same period was four times greater at $8 \mathrm{~cm}$. The concluded growth of females at 14 years is also shown in Table 3 because the correlation between height at 14 and 18 years among females was considerably stronger $(r=0.91, P<0 \cdot 001)$ than among males $(r=0 \cdot 72, P<0 \cdot 001)$. Correlations for weight were very similar to those of height $(r=0.64, P<0.001$ for males and females between 7 and 18 years). Correlations between BMI at different ages were weaker than for weight and height $(r=0.58, P<0.001$ for males and $r=0.59, P<0.001$ for females between 7 and 18 years) and the correlations among shorter periods were again slightly stronger for males than for females. The correlations indicated that BMI at 11 or 14 years explained $49-69 \%$ of the variability in BMI at 18 years, while BMI at 7 years explained only around $34 \%$ of the variability in BMI at 18 years for males and females. In comparison to all other measures, TSF showed the weakest correlations (Table 3 ) between 7 and 18 years $(r=0 \cdot 39, P<0 \cdot 001$ for males and $r=0 \cdot 35, P<0 \cdot 001$ for females). Stronger correlations were again observable among males and over shorter terms; for example, the correlations between TSF at 7 and 11 years were stronger than the correlations between TSF at 7, 14 or 18 years. The correlations indicated that only $12-25 \%$ of the variability in TSF at 18 years 
Table 4 BMI outcome at 18 years for the normal, overweight and obese 7-, 11- and 14-year-olds

\begin{tabular}{|c|c|c|c|c|c|c|c|c|c|c|c|c|c|c|c|c|}
\hline \multirow[b]{3}{*}{ BMI group } & \multicolumn{8}{|c|}{ Males at age 18 years } & \multicolumn{8}{|c|}{ Females at age 18 years } \\
\hline & \multicolumn{2}{|c|}{ Normal } & \multicolumn{2}{|c|}{ Overweight } & \multicolumn{2}{|c|}{ Obese } & \multicolumn{2}{|c|}{ Total $(n)$} & \multicolumn{2}{|c|}{ Normal } & \multicolumn{2}{|c|}{ Overweight } & \multicolumn{2}{|c|}{ Obese } & \multicolumn{2}{|c|}{ Total $(n)$} \\
\hline & $\%$ & $n$ & $\%$ & $n$ & $\%$ & $n$ & $\%$ & $n$ & $\%$ & $n$ & $\%$ & $n$ & $\%$ & $n$ & $\%$ & $n$ \\
\hline Age 7 years & & 1573 & & 479 & & 60 & & & & 1982 & & 250 & & 35 & & \\
\hline Normal & $82 \cdot 7$ & & $16 \cdot 4$ & & 0.9 & & $100 \cdot 0$ & 1712 & $93 \cdot 5$ & & $6 \cdot 3$ & & $0 \cdot 3$ & & $100 \cdot 0$ & 1871 \\
\hline Overweight & $47 \cdot 0$ & & $45 \cdot 9$ & & $7 \cdot 2$ & & $100 \cdot 0$ & 279 & $65 \cdot 9$ & & $29 \cdot 7$ & & $4 \cdot 4$ & & $100 \cdot 0$ & 296 \\
\hline Obese & $22 \cdot 3$ & & $57 \cdot 9$ & & $19 \cdot 8$ & & $100 \cdot 0$ & 121 & $38 \cdot 0$ & & $45 \cdot 0$ & & $17 \cdot 0$ & & $100 \cdot 0$ & 100 \\
\hline Age 11 years & & 1441 & & 426 & & 49 & & & & 1807 & & 224 & & 31 & & \\
\hline Normal & $86 \cdot 5$ & & $13 \cdot 3$ & & $0 \cdot 2$ & & $100 \cdot 0$ & 1471 & $95 \cdot 0$ & & 4.9 & & $0 \cdot 1$ & & $100 \cdot 0$ & 1686 \\
\hline Overweight & $43 \cdot 0$ & & $50 \cdot 6$ & & $6 \cdot 4$ & & $100 \cdot 0$ & 358 & $59 \cdot 9$ & & $36 \cdot 1$ & & $4 \cdot 0$ & & $100 \cdot 0$ & 327 \\
\hline Obese & $16 \cdot 1$ & & $57 \cdot 5$ & & $26 \cdot 4$ & & $100 \cdot 0$ & 87 & $18 \cdot 4$ & & $49 \cdot 0$ & & $32 \cdot 7$ & & $100 \cdot 0$ & 49 \\
\hline Age 14 years & & 1573 & & 479 & & 60 & & & & 1982 & & 250 & & 35 & & \\
\hline Normal & $87 \cdot 8$ & & $12 \cdot 2$ & & $0 \cdot 0$ & & $100 \cdot 0$ & 1663 & $95 \cdot 1$ & & $4 \cdot 8$ & & $0 \cdot 1$ & & $100 \cdot 0$ & 1977 \\
\hline Overweight & $28 \cdot 0$ & & $62 \cdot 9$ & & $9 \cdot 1$ & & $100 \cdot 0$ & 372 & $38 \cdot 4$ & & $53 \cdot 3$ & & $8 \cdot 2$ & & $100 \cdot 0$ & 255 \\
\hline Obese & $11 \cdot 7$ & & $54 \cdot 5$ & & $33 \cdot 8$ & & $100 \cdot 0$ & 77 & $8 \cdot 6$ & & $54 \cdot 3$ & & $37 \cdot 1$ & & $100 \cdot 0$ & 35 \\
\hline
\end{tabular}

Table 5 Percentages within BMI groups at earlier ages according to BMI status at 18 years

\begin{tabular}{|c|c|c|c|c|c|c|c|c|c|c|c|c|}
\hline \multirow[b]{3}{*}{ BMI group* } & \multicolumn{6}{|c|}{ Males at age 18 years } & \multicolumn{6}{|c|}{ Females at age 18 years } \\
\hline & \multicolumn{2}{|c|}{ Normal } & \multicolumn{2}{|c|}{ Overweight } & \multicolumn{2}{|c|}{ Obese } & \multicolumn{2}{|c|}{ Normal } & \multicolumn{2}{|c|}{ Overweight } & \multicolumn{2}{|c|}{ Obese } \\
\hline & $\%$ & $n$ & $\%$ & $n$ & $\%$ & $n$ & $\%$ & $n$ & $\%$ & $n$ & $\%$ & $n$ \\
\hline Age 7 years & & 1573 & & 479 & & 60 & & 1982 & & 250 & & 35 \\
\hline Normal & $90 \cdot 0$ & & $58 \cdot 7$ & & $26 \cdot 7$ & & $88 \cdot 2$ & & $46 \cdot 8$ & & $14 \cdot 3$ & \\
\hline Overweight & $10 \cdot 0$ & & $41 \cdot 3$ & & $73 \cdot 3$ & & $11 \cdot 8$ & & $53 \cdot 2$ & & $85 \cdot 7$ & \\
\hline Obese & $1 \cdot 7$ & & $14 \cdot 6$ & & $40 \cdot 0$ & & 1.9 & & $18 \cdot 0$ & & $48 \cdot 6$ & \\
\hline Age 11 years & & 1441 & & 426 & & 49 & & 1807 & & 224 & & 31 \\
\hline Normal & $88 \cdot 3$ & & $45 \cdot 8$ & & $6 \cdot 1$ & & $88 \cdot 7$ & & $36 \cdot 6$ & & $6 \cdot 5$ & \\
\hline Overweight & $11 \cdot 7$ & & $54 \cdot 2$ & & 93.9 & & $11 \cdot 3$ & & $63 \cdot 4$ & & 93.5 & \\
\hline Obese & $1 \cdot 0$ & & $11 \cdot 7$ & & $46 \cdot 9$ & & 0.5 & & $10 \cdot 7$ & & $51 \cdot 6$ & \\
\hline Age 14 years & & 1573 & & 479 & & 60 & & 1982 & & 250 & & 35 \\
\hline Normal & $92 \cdot 8$ & & $42 \cdot 4$ & & 0.0 & & 94.9 & & $38 \cdot 0$ & & $2 \cdot 9$ & \\
\hline Overweight & $7 \cdot 2$ & & $57 \cdot 6$ & & $100 \cdot 0$ & & $5 \cdot 1$ & & $62 \cdot 0$ & & $97 \cdot 1$ & \\
\hline Obese & 0.6 & & $8 \cdot 8$ & & $43 \cdot 3$ & & 0.2 & & $7 \cdot 6$ & & $37 \cdot 1$ & \\
\hline
\end{tabular}

${ }^{*} \mathrm{BMl}$ groups are not mutually exclusive, i.e. overweight includes also obesity.

was explained by TSF at 7,11 or 14 years. Correlations of TSF with height, weight and BMI suggested that TSF correlates best with BMI and that correlations are largest at 11 years in males $(r=0 \cdot 77, P<0 \cdot 001)$ and females $(r=0 \cdot 70$, $P<0 \cdot 001)$. High correlations were also observed between TSF and weight at all ages in both sexes, while correlations of TSF with height proved to be small $(r<0 \cdot 29, P<0 \cdot 001)$.

\section{BMI outcome for obese and overweight children}

The data in Table 4 show whether overweight and obese 7-years-olds became overweight 18-year-olds, giving the percentage of children who were subsequently in each BMI group according to the IOTF cut-off points at 18 years. The general trend was that the higher the BMI group, the higher was the probability of being obese at 18 years. For example, $17 \cdot 3 \%$ of 7 -year-old males of normal weight were obese or overweight at 18 years compared with $53 \cdot 1 \%$ who were overweight or $77 \cdot 7 \%$ who were obese at 7 years. The chances of an obese 7-year-old becoming an obese 18-yearold increased consistently with age. For obese males at 7 years of age, the percentage of those who were obese at
18 years increased from $19 \cdot 8 \%$ at 7 years to $26 \cdot 4 \%$ at 11 years and $33 \cdot 8 \%$ at 14 years. The trends among females were similar with $17 \cdot 0 \%$ of obese 18 -year-olds at 7 years, $32 \cdot 7 \%$ at 11 years and $37 \cdot 1 \%$ at 14 years.

\section{Previous BMI of obese 18-year-olds}

The data in Table 5 show the percentages for BMI groups of those 18-year-olds who had been in different BMI groups in childhood and adolescence in order to assess whether obese 18-year-olds were obese as children. At every age, the majority (around 90\%) of 18-year-olds of normal weight would be identified as children of normal weight. In contrast, between $41.3 \%$ and $57 \cdot 6 \%$ of overweight 18 -year-old males, and between $53.2 \%$ and $63.4 \%$ of overweight or obese females would be identified as overweight children. In both sexes, there was a very high percentage of obese individuals at 18 years of age who would have been identified as overweight or obese individuals at earlier ages. The percentage grew with age in both sexes; among males, $73 \cdot 3 \%$ of obese 18 -year-olds were overweight or obese at 7 years, $93.9 \%$ at 11 years 
and $100 \%$ at 14 years, while among females $85.7 \%$ of obese 18-year-olds were obese at 7 years, $93.5 \%$ at 14 years and $97 \cdot 1 \%$ at 14 years.

\section{Discussion}

It has already been established that tracking childhood obesity beyond early adult age is a serious limitation of the literature to date $\mathrm{e}^{(24,26)}$, but the lack of studies from developing countries and the countries that experienced abrupt and major socio-political and economical changes in recent years seems to be equally limiting ${ }^{(27)}$. Slovenia is a country that has experienced enormous socio-political and economical changes in the last 20 years, which strongly influenced the lifestyles, nutritional habits of children and youth, and their physical development ${ }^{(38-41)}$.

Studies in the USA and Europe that tracked obesity from childhood to adulthood generally found that about onethird of overweight and obese children remained overweight and obese as adults ${ }^{(24,42-46)}$. In our cohort study, the percentage of overweight and obese 7-year-olds who became overweight or obese 18-year-olds was considerably higher (over 65\% among males and below 50\% among females). Our findings, which are more alarming, might be the outcome of the recent cohort, since most of the previous studies used cohorts from the 1950s and 1960s. The young adults included in our cohort probably lived in a very different environment as children than the ones in the older cohorts, especially regarding the abundance of fat- and sugar-rich food, availability of media and information technology and sedentary lifestyles.

In addition, we found that excess weight and obesity track slightly more consistently in females than in males, because obese and overweight females were more likely to remain in the same BMI group or move to a lower BMI group (obese to overweight and overweight to normal, respectively). The reason for this phenomenon remains unclear but it could be that body image, especially weight management, is more important to girls than to boys $^{(47-52)}$, and they put more effort into maintaining or lowering their weight; boys, who more often moved from the lower to the higher BMI group, show much lower concern in this matter. Another possible reason that might explain this phenomenon is the use of the IOTF standard, which could misclassify some Slovenian children and adolescents because this standard was constructed on the basis of data from countries other than Slovenia.

In comparison to some other studies ${ }^{(25,42,43)}$, BMI in our population is well predicted from childhood. This is suggested by large correlations (above $r=0 \cdot 50$ ) between childhood and young adulthood BMI and a large proportion of obese and overweight 18-year-olds identified from childhood. According to the IOTF cut-off points for obesity, $40 \cdot 0 \%$ of Slovenian 18-year-old obese males and $48.6 \%$ females would have been identified from their
BMI at 7 years. The percentage identified increased with years, and it is notable that a large majority of the obese 18 -year-olds had already been obese or overweight at 14 years $(89.3 \%$ of boys and $91.0 \%$ of girls). The data suggest that children who today enter secondary schools obese are almost certain to remain so until the end of their schooling. Although Serdula et al. ${ }^{(47)}$ estimated that less than a half of adult obesity can be attributed to childhood obesity, and our data support this finding, it should be noted that (taking into account overweight and obese BMI groups combined) over $73 \%$ of males and over $85 \%$ of 18 -year-old obese females would have been classified as overweight or obese as early as 7 years, and the percentage identified would have increased to over $90 \%$ with age in both sexes. In addition, the correlations of BMI at 18 years with BMI at earlier ages suggest that between one-third (at 7 years) and two-thirds (at 14 years) of the variability in BMI at 18 years was explained by BMI in childhood.

Finally, in contrast with the large correlations of height, weight and BMI between childhood and adulthood, those for TSF were only medium $(r<0 \cdot 50, P<0 \cdot 001)$, except for the correlation of TSF at 11 and 14 years, where the correlations were large among females $(r=0.62, P<$ $0 \cdot 001)$ and even larger among males $(r=0 \cdot 70, P<0 \cdot 001)$. This finding is congruent with other findings, which suggested that precision of obesity prediction by TSF is very low up to late childhood and becomes somewhat better in adolescence, and that correlations are usually higher for males ${ }^{(22)}$. This phenomenon could be attributed to the known methodological problems ${ }^{(53)}$. It has been reported previously that skinfold thickness measurements in obese subjects have poor reliability ${ }^{(54)}$, and that skin thickness and skinfold compressibility vary by age, by site and possibly also by $\operatorname{sex}^{(55-58)}$. This suggests that using TSF curves for the classification of overweight and obese children should be used with all these problems in mind and that the use of BMI curves is more practical for the tracking of obesity from childhood to adulthood.

The child-to-adult relationship for obesity will continue to be of interest to researchers and policy makers, because policies to prevent childhood and adult obesity are under discussion in many countries ${ }^{(59)}$. The evidence presented in the present study suggests that the prevention of adulthood obesity should focus on the identification and treatment of high-risk groups in childhood and adolescence. It is especially important to prevent and treat overweight and obesity at a young age, because children and adolescents of normal weight are very likely to retain normal weight. However, the relative risk for becoming an obese adult is greatly increased for those who are already obese or overweight as children or adolescents. From an epidemiological viewpoint, these are the critical periods when preventive measures such as nutrition and physical activity management could be applied. 


\section{Acknowledgements}

Sources of funding: This study was funded by the Slovenian Ministry of Education and Sport. Conflict of interest declaration: The authors have no conflict of interest to declare. Authorship responsibilities: G.S. performed all data analysis and wrote the manuscript; J.S. wrote the protocol of the study and authored the SLOFIT system for monitoring the physical and motor development of children and youth.

\section{References}

1. World Health Organization (1998) Obesity: Preventing and Managing the Global Epidemic. Geneva: WHO.

2. Lew EA \& Garfinkel L (1979) Variations in mortality by weight among 750000 men and women. J Chronic Dis 32, 563-576.

3. Hu G, Tuomilehto J, Silventoinen K et al. (2005) The effects of physical activity and body mass index on cardiovascular, cancer and all-cause mortality among 47212 middle-aged Finnish men and women. Int J Obes 29, 894-902.

4. El-Serag H (2008) The association between obesity and GERD: a review of the epidemiological evidence. Dig Dis Sci 53, 2307-2312.

5. Cho E, Manson JE, Stampfer MJ et al. (2002) A prospective study of obesity and risk of coronary heart disease among diabetic women. Diabetes Care 25, 1142-1148.

6. Mokdad AH, Ford ES, Bowman BA et al. (2003) Prevalence of obesity, diabetes, and obesity-related health risk factors, 2001. JAMA 289, 76-79.

7. Michaud DS, Giovannucci E, Willett WC et al. (2001) Physical activity, obesity, height, and the risk of pancreatic cancer. JAMA 286, 921-929.

8. Thomsen SF, Ulrik CS, Kyvik KO et al. (2007) Association between obesity and asthma in a twin cohort. Allergy 62, 1199-1204.

9. Zimmet P, Alberti KG \& Shaw J (2001) Global and societal implications of the diabetes epidemic. Nature $\mathbf{4 1 4}$, 782-787.

10. Arslanian S (2002) Type 2 diabetes in children: clinical aspects and risk factors. Horm Res Suppl 57, 19-28.

11. Freedman DS, Dietz WH, Srinivasan SR et al. (1999) The relation of overweight to cardiovascular risk factors among children and adolescents: the Bogalusa Heart Study. Pediatrics 103, 1175-1182.

12. Harrell JS, Jessup A \& Greene N (2006) Changing our future: obesity and the metabolic syndrome in children and adolescents. J Cardiovasc Nurs 21, 322-330.

13. Weiss R, Dziura J, Burgert TS et al. (2004) Obesity and the metabolic syndrome in children and adolescents. $N$ Engl J Med 350, 2362-2374.

14. Gilliland FD, Berhane K, Islam T et al. (2003) Obesity and the risk of newly diagnosed asthma in school-age children. Am J Epidemiol 158, 406-415.

15. Colditz GA (1999) Economic costs of obesity and inactivity. Med Sci Sports Exerc Suppl 31, 663-667.

16. Wolf AM \& Colditz GA (1998) Current estimates of the economic cost of obesity in the United States. Obes Res $\mathbf{6}$, 97-106.

17. Thompson D \& Wolf AM (2001) The medical-care cost burden of obesity. Obes Rev 2, 189-197.

18. Wang G \& Dietz WH (2002) Economic burden of obesity in youths aged 6 to 17 years: 1979-1999. Pediatrics 109, E81.
19. Seidell JC (1998) Societal and personal costs of obesity. Exp Clin Endocrinol Diabetes Suppl 106, 7-9.

20. Whitaker RC, Wright JA, Pepe MS et al. (1997) Predicting obesity in young adulthood from childhood and parental obesity. N Engl J Med 337, 869-873.

21. Kotani K, Nishida M, Yamashita S et al. (1997) Two decades of annual medical examinations in Japanese obese children: do obese children grow into obese adults? Int J Obes Relat Metab Disord 21, 912-921.

22. Clarke WR \& Lauer RM (1993) Does childhood obesity track into adulthood? Crit Rev Food Sci Nutr 33, 423-430.

23. Magarey AM, Daniels LA, Boulton TJ et al. (2003) Predicting obesity in early adulthood from childhood and parental obesity. Int J Obes Relat Metab Disord 27, 505-513.

24. Guo SS, Huang C, Maynard LM et al. (2000) Body mass index during childhood, adolescence and young adulthood in relation to adult overweight and adiposity: the Fels Longitudinal Study. Int J Obes Relat Metab Disord 24, $1628-1635$.

25. Power C, Lake JK \& Cole TJ (1997) Body mass index and height from childhood to adulthood in the 1958 British born cohort. Am J Clin Nutr 66, 1094-1101.

26. Kemper HC, Post GB, Twisk JW et al. (1999) Lifestyle and obesity in adolescence and young adulthood: results from the Amsterdam Growth And Health Longitudinal Study (AGAHLS). Int J Obes Relat Metab Disord Suppl 23, 34-40.

27. Williams S, Davie G \& Lam F (1999) Predicting BMI in young adults from childhood data using two approaches to modelling adiposity rebound. Int J Obes Relat Metab Disord 23, 348-354.

28. Kvaavik E, Tell GS \& Klepp KI (2003) Predictors and tracking of body mass index from adolescence into adulthood: follow-up of 18 to 20 years in the Oslo Youth Study. Arch Pediatr Adolesc Med 157, 1212-1218.

29. Dietz WH (1997) Periods of risk in childhood for the development of adult obesity - what do we need to learn? J Nutr 127, 1884-1886.

30. Dietz WH (1994) Critical periods in childhood for the development of obesity. Am J Clin Nutr 59, 955-959.

31. Rolland-Cachera MF, Deheeger M, Bellisle F et al. (1984) Adiposity rebound in children: a simple indicator for predicting obesity. Am J Clin Nutr 39, 129-135.

32. Charney E, Goodman HC, McBride M et al. (1976) Childhood antecedents of adult obesity. Do chubby infants become obese adults? N Engl J Med 295, 6-9.

33. Stettler N, Zemel BS, Kumanyika S et al. (2002) Infant weight gain and childhood overweight status in a multicenter, cohort study. Pediatrics 109, 194-199.

34. Whitaker RC, Pepe MS, Wright JA et al. (1998) Early adiposity rebound and the risk of adult obesity. Pediatrics 101, E5.

35. Strel J, Ambrožič F, Kondrič M et al. (1997) Sports Educational Chart. Ljubljana, Slovenia: Ministry of Education and Sport.

36. Cole TJ, Bellizzi MC, Flegal KM et al. (2000) Establishing a standard definition for child overweight and obesity worldwide: international survey. BMJ 320, 1240-1243.

37. Tanner JM, Whitehouse RH, Marubini E et al. (1976) The adolescent growth spurt of boys and girls of the Harpenden Growth Study. Ann Hum Biol 3, 109-126.

38. Wang Y, Ge K \& Popkin BM (2000) Tracking of body mass index from childhood to adolescence: a 6-years follow-up study in China. Am J Clin Nutr 72, 1018-1024.

39. Kovač M, Leskošek B \& Strel J (2008) Overweight and obesity trends in Slovenian boys from 1991 to 2006. Acta Univ Palacki Olomuc Gymn 38, 17-26.

40. Jurak G (2006) Sporting lifestyle $v$. 'cigarettes \& coffee' lifestyle of Slovenian high school students. Anthropol Noteb 12, 79-95. 
41. Jurak G, Kovač M \& Strel J (2002) How Slovene primary school pupils spend their summer holidays. Kinesiol Slov $\mathbf{8}$, $35-43$.

42. Lake JK, Power C \& Cole TJ (1997) Child to adult body mass index in the 1958 British birth cohort: associations with parental obesity. Arch Dis Child 77, 376-381.

43. Rolland-Cachera MF, Deheeger M, Guilloud-Bataille M et al. (1987) Tracking the development of adiposity from one month of age to adulthood. Ann Hum Biol 14, 219-229.

44. Rolland-Cachera MF, Bellisle F \& Sempe M (1989) The prediction in boys and girls of the weight/height index and various skinfold measurements in adults: a two-decade follow-up study. Int J Obes 13, 305-311.

45. Guo SS, Chumlea WC, Roche AF et al. (1997) Age- and maturity-related changes in body composition during adolescence into adulthood: the Fels Longitudinal Study. Int J Obes Relat Metab Disord 21, 1167-1175.

46. DiPietro L, Mossberg HO \& Stunkard AJ (1994) A 40-year history of overweight children in Stockholm: life-time overweight, morbidity, and mortality. Int $J$ Obes Relat Metab Disord 18, 585-590.

47. Serdula MK, Ivery D, Coates RJ et al. (1993) Do obese children become obese adults? A review of the literature. Prev Med 22, 167-177.

48. Nowak M, Speare R \& Crawford D (1996) Gender differences in adolescent weight and shape-related beliefs and behaviour. J Paediatr Child Health 32, 148-152.

49. Folk L, Pedersen J \& Cullari S (1993) Body satisfaction and self-concept of third- and sixth-grade students. Percept Mot Skills 76, 547-553.
50. Sarlio-Lähteenkorva S, Pärna K, Palosuo H et al. (2003) Weight satisfaction and self-esteem among teenagers in Helsinki, Moscow and Tallinn. Eat Weight Disord 8, 289-295.

51. McCabe M \& Ricciardelli L (2003) Body image and strategies to lose weight and increase muscle among boys and girls. Health Psychol 22, 39-46.

52. Davison T \& McCabe M (2006) Adolescent body image and psychosocial functioning. J Soc Psychol 146, 15-30.

53. Must A, Dallal GE \& Dietz WH (1991) Reference data for obesity: 85th and 95th percentiles of body mass index (wt) ht2) and triceps skinfold thickness. Am J Clin Nutr 53, 839-846.

54. Forbes GB (1964) Lean body mass and fat in obese children. Pediatrics 34, 308-314.

55. Martin AD, Ross WD, Drinkwater DT et al. (1985) Prediction of body fat by skinfold calliper: assumptions and cadaver evidence. Int J Obes Suppl 9, 31-39.

56. Roche AF (1987) Some aspects of the criterion methods for the measurement of body composition. Hum Biol 59, 209-220.

57. Himes JH, Roche AF \& Siervogel RM (1979) Compressibility of skinfolds and the measurement of subcutaneous fatness. Am J Clin Nutr 32, 1734-1740.

58. Clegg EJ \& Kent C (1967) Skinfold compressibility in young adults. Hum Biol 39, 418-429.

59. Commission of the European Communities (2007) White Paper on a Strategy for Europe on Nutrition, Overweight and Obesity Related Health Issues. Brussels: Commission of the European Communities. 